\title{
Pengunaan Model Pembelajaran POE2WE dengan Bantuan aplikasi Zenius Education untuk Meningkatkan Pemahaman Konsep dalam Pembelajaran Fisika
}

\author{
Yunita $^{1}$, Nana $^{2}$ \\ ${ }^{1}$ Mahasiswa Program Studi Pendidikan Fisika, Universitas Siliwangi \\ ${ }^{2}$ Dosen Program Studi Pendidikan Fisika, Universtias Siliwangi \\ Universitas Siliwangi Tasikmalaya \\ *Email: yunitauni217@gmail.com
}

\begin{abstract}
The purpose of this paper is to describe the use of the POE2WE Learning Model with the help of the Zenius Education application to enhance understanding of concepts in physics learning. This writing is motivated by the rise of the use of online tutoring one of which is zenius education which is currently accessible for free. The POE2WE model as a solution process through a constructivist approach is accompanied by the use of the Zenius Education application so that students become motivated by increasing understanding of concepts and can improve their learning outcomes. The method used in this paper is the study of literature by studying some literature to be analyzed and made conclusions. The results of this paper that the POE2WE learning model and the use of the Zenius Education application can improve understanding of physics learning concepts, because both the POE2WE model is applied to students in several stages starting from problem solving until the learning concept is found and then linked to everyday life, this can improve understanding of concepts in students. Likewise with the Zenius Education application that explains the concepts and explained also in detail so that students will better understand the formulas used in learning physics.
\end{abstract}

Keywords: POE2WE, zenius education, Physics Learning

ABSTRAK: Tujuan penulisan ini untuk mendeskripsikan Pengunaan Model Pembelajaran POE2WE dengan Bantuan aplikasi Zenius Education untuk Meningkatkan Pemahaman Konsep dalam Pembelajaran Fisika. Penulisan ini dilatarbelakangi oleh maraknya peggunaan bimbingan belajar online salah satunya yaitu zenius education yang saat ini dapat diakses secara gratis . Model POE2WE sebagai proses solusi melalui pendekatan konstruktivistik disertai dengan penggunaan aplikasi Zenius Education sehingga peserta didik menjadi termotivasi dengan menambah pemahaman konsep dan dapat meningkatkan hasil belajar mereka. Metode yang digunakan dalam penulisan ini adalah studi kepustakaan dengan mengkaji beberapa literatur untuk dianalisis dan dibuat kesimpulan. Hasil penulisan ini bahwa model pembelajaran POE2WE dan penggunaan aplikasi Zenius Education dapat meningkatkan pemahaman konsep pembelajaran fisika, karena baik model POE2WE yang diterapkan untuk peserta didik dalam beberapa tahap yang berawal dari pemecahan masalah sampai ditemukan konsep pembelajarannya lalu dihubungkan pada kehidupan sehari-hari, ini dapat meningkatkan pemahaman konsep pada peserta didik. Begitupun dengan aplikasi Zenius Education yang menjelaskan dengan konsep dan dijelaskan pula secara detail sehingga peserta didik akan lebih paham pada rumus-rumus yang digunakan dalaam pembelajaran fisika.

Kata Kunci : POE2WE, zenius education, Pembelajaran Fisika

\section{PENDAHULUAN}


Pada era globalisasi saat ini, perkembangan internet begitu pesat. Perkembangan teknologi dan internet menjadi kemunculan berbagai inovasi baru di suatu negara. Tren ini terkait dengan alat yang memiliki kreativitas yang mampu mendesain materi dan mendesain pembelajaran menjadi lebih baik. Banyak sekali keuntungan yang diperoleh dari penggunaan internet dan tekonolgi salah satunya informasi dapat dengan mudah didapat dan disebar. Keuntungan tersebut juga berdampak kepada dunia pendidikan yaitu semakin mudahnya peserta didik mendapatkan bahan pembelajaran dengan cepat tanpa batasan tempat, jarak, ruang dan waktu.

Pendidikan merupakan hal yang penting bagi setiap individu. Di Indonesia, semua penduduk wajib mengikuti program wajib belajar pendidikan dasar selama dua belas tahun. Menurut Brush, Glazewski dan Hew (2008), salah satu bentuk teknologi dengan dunia pendidikan adalah Information and Communication Technologies (ICT). Dalam dunia pendidikan, ICT digunakan sebagai alat bagi siswa untuk menemukan topik pembelajaran, memecahkan masalah dan memberikan solusi dalam permasalahan pada proses pembelajaran. ICT sebagai media pendidikan adalah e-learning salah satunya zenius education.

Dalam proses pembelajaran, peserta didik selalu diarahkan dan dituntut untuk bisa memahami materi pembelajaran dengan sebaik-baiknya. Namun, faktanya selama proses pembelajaran berlangsung peserta didik tidak selalu menyerap dan memahami informasi yang telah disampaikan dengan sepenuhnya, terlebih lagi pada mata pelajaran Fisika yang memuat banyak konsep ilmiah dan dianggap sebagai sesuatu yang menakutkan bagi peserta didik. Oleh karena itu, dengan bantuan aplikasi Zenius Education yang merupakan salah satu startup dengan platform pendidikan pertama yang beroperasi pada tahun 2004 yang berfokus pada layanan berbasis pendidikan yang mengajarkan konsep bukan hanya rumus cepat saja, sehingga dengan menggunakan aplikasi Zenius Education peserta didik diharapkan dapat lebih memahami suatu konsep pembelajaran khususnya fisika.

Penyampaian pembelajaran dengan menggunakan teknologi harus memperhatikan berbagai konten yang sesuai dengan batasan umurnya agar tidak terfokus dari inovasi yang digunakan. Namun dalam hal ini, tidak begitu mudah untuk menyebarkan berbagai teknologi yang inovatif di sekolah-sekolah dikarenakan berbagai paham dan sejarah sekolah yang berpengaruh pada pelaksanaannya (Nana, 2018: 191).

Selain dengan bantuan aplikasi Zenius Education, peran pengajar di sekolah juga sangan penting dalam pembelajaran. Peran pengajar di sekolah merupakan hal yang paling pokok untuk hasil pembelajaran. Hasil pembelajaran di sekolah dapat bergantung pada model pembelajarn yang diterapkan oleh pengajar. Secara garis besar penggunaan model juga harus fleksibel karena didasarkan pada situasi dan kondisi di sekolah dengan tujuan untuk merangsang daya kreatif siswa (Yu Je Lee, 2011: 93). Selain model pembelajaran yang digunakan, motivasi peserta didik dalam pembelajaran juga menjadi hal yang sangat penting. Cara untuk meningkatkan motivasi siswa dalam belajar yaitu dengan memberikan berbagai masalah-masalah yang berbeda-beda (Nana, 2018: 191).

Masalah-masalah harus memenuhi kriteria yaitu mampu menciptakan kreatif siswa, dibuat untuk dipecahkan secara berkelompok, berkaitan dengan kekuatan diri sehingga siswa tidak hanya mampu mencerna permasalahan tetapi cara bersosialisasi dengan terlibat dalam diskusi (Valqui Vidal, 2010: 407408). Masalah tersebut dapat diselesaikan dengan menggunakan model pembelajaran POE2WE.

Model pembelajaran Prediction, Observation, Explanation, Elaboration, Write and Evaluation (POE2WE) dikembangkan dari model pembelajaran POEW dan model pembelajaran Fisika dengan Pendekatan Konstruktivistik. Model POE2WE merupakan model pembelajaran yang dikembangkan untuk mengetahui pemahaman siswa mengenai suatu konsep dengan pendekatan konstruktivistik. Model ini membangun pengetahuan dengan urutan proses terlebih dahulu meramalkan atau memprediksi solusi dari permasalahan, melakukan eksperimen untuk membuktikan prediksi, kemudian menjelaskan hasil eksperimen yang diperoleh secara lisan maupun tertulis, membuat contoh penerapan dalam kehidupan sehari-hari, menuliskan hasil diskusi dan membuat evaluasi tentang pemahaman siswa baik secara lisan maupun tertulis (Nana, 2018) 
Berdasarakan latar belakang tersebut, maka disusunlah penelitan yang berjudul "Pengunaan Model Pembelajaran POE2WE dengan Bantuan aplikasi Zenius Education untuk Meningkatkan Pemahaman Konsep dalam Pembelajaran Fisika"

\section{METODE PENELITIAN}

Metode yang digunakan dalam artikel ini adalah studi literatur atau studi pustaka. Data dikumpulkan dan dianalisis disajikan dalam hasil dan pembahasan untuk menarik kesimpulan.

\section{HASIL DAN \\ PEMBAHASAN 3.1 Model POE2WE}

Model pembelajaran Prediction, Observation, Explanation, Elaboration, Write dan Evaluation (POE2WE) dikembangkan dari model pembelajaran POEW dan model pembelajaran Fisika dengan Pendekatan Konstruktivistik. Pengembangan ini dilakukan untuk sebagai penyempurnaan kedua model sebelumnya. Model POE2WE merupakan model pembelajaran yang dikembangkan untuk mengetahui pemahaman peserta didik mengenai suatu konsep dengan pendekatan konstruktivistik. Model ini membangun pengetahuan dengan urutan proses yaitu meramalkan atau memprediksi solusi dari permasalahan, melakukan eksperimen untuk membuktikan prediksi, kemudian menjelaskan hasil eksperimen yang diperoleh secara lisan maupun tertulis, membuat contoh penerapan dalam kehidupan sehari-hari, menuliskan hasil diskusi dan memuat evaluasi tentang pemahaman peserta didik baik secara lisan maupun tertulis (Nana et al., 2014; 2016).

Model pembelajaran POE2WE dapat menjadikan peserta didik sebagai subjek di dalam pembelajaran. peserta didik secara aktif menemukan suatu konsep melalui pengamatan atau eksperimen secara langsung, bukan dari menghafal buku materi maupun penjelasan dari guru. Model ini memungkinkan peserta didik aktif dalam proses pembelajaran, memberikan kesempatan kepada peserta didik untuk konstruktivistik pengetahuannya, mengkomunikasikan pemikirannya dan menuliskan hasil diskusinya sehingga peserta didik lebih menguasai dan memahami konsep yang akan berdampak pada peningkatan prestasi belajar peserta didik Model ini memberikan kesempatan kepada peserta didik untuk melakukan konstruksi pengetahuan yang dimilikinya, melakukan pengamatan terhadap fenomena serta mengkomunikasikan gagasan yang dia perolah dari proses diskusi sehingga peserta didik akan lebih mudah menguasai konsep yang diajarkan (Nana, 2014,2016; Nana et al., 2014; Nana dan Surahman, 2019, 2020; Permatasari, 2011; Rahayu et al., 2013; Samosir, 2010).

Penggabungan tahapan-tahapan pembelajaran model POEW dan model pembelajaran Fisika dengan Pendekatan Konstruktivistik maka dapat di susun langkah-langkah pembelajaran model POE2WE secara terinci sebagai berikut (Nana dan Surahman, 2019; 2020):

a) Prediction

Tahap prediction yaitu peserta didik membuat prediksi atau dugaan awal terhadap suatu permasalahan. Permasalahan yang ditemukan berasal dari pertanyaan dan gambar tentang materi yang disampaikan oleh guru yang ada di Lembar Kerja peserta didik (LKS)/bukupeserta didik sebelum peserta didik membuat prediksi. Pembuatan prediksi jawaban tahap Prediction pada model POEW identik dengan fase Engagenent pada pendekatan konstruktivistik. Guru mengajukan pertanyaan yang dapat mendorong peserta didik untuk dapat membuat prediksi atau jawaban sementara dari suatu permasalahan.

b) Observation 
Tahap Observation yaitu untuk membuktikan prediksi yang telah di buat oleh peserta didik. Peserta didik diajak melakukan eksperimen berkaitan dengan masalah atau persoalan yang di temukan. Selanjutnya peserta didik mengamati apa yang terjadi, kemudian peserta didik menguji kebenaran dari dugaan sementara yang telah dibuat. Tahap Observation pada model POEW identik dengan fase Exploration pada pendekatan konstruktivistik.

c) Explanation

Tahap Explanation atau menjelaskan yaitu peserta didik memberikan penjelasan terhadap hasil eksperimen yang telah dilakukan. Penjelasan dari peserta didik dilakukan melalui diskusi dengan anggota kelompok kemudian tiap kelompok mempresentasikan hasil diskusinya di depan kelas. Jika prediksi yang di buat peserta didik ternyata terjadi di dalam eksperimen, maka guru membimbing peserta didik merangkum dan memberi penjelasan untuk menguatkan hasil eksperimen yang dilakukan. Namun jika prediksi peserta didik tidak terjadi dalam eksperimen, maka guru membantu peserta didik mencari penjelasan mengapa prediksi atau dugaannya tidak benar. Tahap explanation identik dengan fase explanation pada pendekatan konstuktivistik.

d) Elaboration

Tahap elaboration yaitu peserta didik membuat contoh atau menerapkan konsep dalam kehidupan sehari-hari. Tahap elaboration di ambil dari pendekatan konstruktivistik. Tahap ini guru medorong peserta didik untuk menerapkan konsep baru dalam situasi baru sehingga peserta didik lebih memahami konsep yang di ajarkan guru. Tahap ini pengembangan dari pendekatan konstruktivistik.

e) Write

Tahap write atau menulis yaitu melakukan komunikasi secara tertulis, merefleksikan pengetahuan dan gagasan yang dimiliki peserta didik Menurut Masingilia dan Wisniowska (1996) dalam (Yamin \& Ansari, 2012) menulis dapat membantu peserta didik untuk mengekspresikan pengetahuan dan gagasan mereka. peserta didik menuliskan hasil diskusi dan menjawab pertanyaan yang ada pada LKS. Selain itu pada tahap write ini, peserta didik membuat kesimpulan dan laporan dari hasil eksperimen. Tahap ini merupakan pengembangan dari model TTW.

\section{f) Evaluation}

Tahap Evaluation yaitu evaluasi terhadap pengetahuan, keterampilan dan perubahan proses berfikir peserta didik. Pada tahap ini peserta didik di evaluasi tentang materi gerak lurus berupa lisan maupun tulisan. Tahap ini merupakan pengembangan dari pendekatan konstruktivistik.

Tabel 1. Sintaks Pengembangan model POE2WE

\begin{tabular}{|c|c|c|c|}
\hline No. & $\begin{array}{l}\text { Sintaks POEW } \\
\text { (Samosir, 2010) }\end{array}$ & $\begin{array}{l}\text { Sintaks Model } \\
\text { Pembelajaran dengan } \\
\text { Pendekatan }\end{array}$ & $\begin{array}{c}\text { Model POE2WE (Nana et al., } \\
\text { 2014) }\end{array}$ \\
\hline & & $\begin{array}{l}\text { Kontruktivistik (Duffy } \\
\text { dan Junassen, 1992) }\end{array}$ & \\
\hline 1. & $\begin{array}{l}\text { (Prediction) } \\
\text { membuat prediksi, }\end{array}$ & $\begin{array}{l}\text { (Engagement }) \\
\text { pendahuluan }\end{array}$ & $\begin{array}{l}\text { (Prediction) } \\
\text { Membuat dugaan atau prediksi. }\end{array}$ \\
\hline
\end{tabular}




\begin{tabular}{|l|l|l|l|} 
& membuat dugaan. & $\begin{array}{l}\text { membuat pertanyaan } \\
\text { menggali pengetahuan } \\
\text { awal peserta didik. }\end{array}$ & $\begin{array}{l}\text { Tahap Engagement identik } \\
\text { dengan Predict pada POEW }\end{array}$ \\
\hline 2. & $\begin{array}{l}\text { (Observation) } \\
\text { Melakukan } \\
\text { penelitian, } \\
\text { pengamatan }\end{array}$ & $\begin{array}{l}\text { Exploration) menguji } \\
\text { prediksi } \text { melakukan dan } \\
\text { mencatat hasil } \\
\text { pengamatan. }\end{array}$ & $\begin{array}{l}\text { (Observation) Melakukan } \\
\text { observasi/pengamatan Tahap } \\
\text { Exploration } \text { identik dengan tahap } \\
\text { observation pada POEW. }\end{array}$ \\
\hline 3. & $\begin{array}{l}\text { (Explanation }) \text { Yaitu } \\
\text { memberi penjelasan }\end{array}$ & $\begin{array}{l}\text { Explation) menjelaskan } \\
\text { konsep dengan kalimat } \\
\text { mereka sendiri }\end{array}$ & $\begin{array}{l}\text { (Explanation } \text { Menjelaskan Pada } \\
\text { tahap } \text { explanation identik dengan } \\
\text { explation pada pendekatan } \\
\text { Konstruktivistik }\end{array}$ \\
\hline 4. & $\begin{array}{l}\text { (Write) Membuat } \\
\text { kesimpulan }\end{array}$ & $\begin{array}{l}\text { (Elaboration) Aplikasi } \\
\text { konsep dalam kehidupan } \\
\text { sehari-hari. }\end{array}$ & $\begin{array}{l}\text { (Elaboration) Aplikasi konsep } \\
\text { dalam kehidupan sehari-hari } \\
\text { merupakan pengembangan dari } \\
\text { pendekatan Konstruktivistik }\end{array}$ \\
\hline
\end{tabular}




\begin{tabular}{|l|l|l|l|}
\hline 5. & & $\begin{array}{l}\text { (Evaluation) Evaluasi } \\
\text { terhadap pengetahuan, } \\
\text { keterampilan dan } \\
\text { perubahan proses berfikir } \\
\text { peserta didik. }\end{array}$ & $\begin{array}{l}\text { (Write) Menuliskan hasil diskusi } \\
\text { sebagai kesimpulan. Merupakan } \\
\text { pengembangan dari model POEW }\end{array}$ \\
\hline 6. & & $\begin{array}{l}\text { (Evaluation) Evaluasi terhadap } \\
\text { efektifitas fase-fase sebelumnya. } \\
\text { Merupakan pengembangan dari } \\
\text { pendekatan Konstruktivistik }\end{array}$ \\
\hline
\end{tabular}

Sumber: Nana, Surahman E. 2019. Pengembangan Inovasi Pembelajaran Digital Menggunakan Model Blended POE2WE di Era Revolusi Industri 4.0. Prosiding SNFA (Seminar Nasional dan Aplikasinya), 82-90.

Tabel 2. Kegiatan Model Pembelajaran Model POE2WE

\begin{tabular}{|c|c|c|}
\hline Fase-fase & Kegiatan Guru & Kegiatan Peserta \\
\hline Prediction & $\begin{array}{l}\text { Menyampaikan tujuan } \\
\text { pembelajaran. } \\
\text { Mengajukan pertanyaan } \\
\text { kepada siswa } \\
\text { Menginventarisir prediksi dan } \\
\text { alasan yang di kemukakan peserta } \\
\text { didik }\end{array}$ & $\begin{array}{l}\text { Memperhatikan penjelasan dari } \\
\text { guru. } \\
\text { Memprediksi Jawaban } \\
\text { pertanyaan dari guru } \\
\text { Mendiskusikan hasil } \\
\text { Prediksinya }\end{array}$ \\
\hline Observation & $\begin{array}{l}\text { Mendorong peserta didik untuk } \\
\text { bekerja secara kelompok } \\
\text { Membagikan LKS } \\
\text { Mengawasi kegiatan percobaan } \\
\text { yang dilakukan oleh peserta didik }\end{array}$ & $\begin{array}{l}\text { Membentuk kelompok } \\
\text { Melakukan percobaan } \\
\text { Mengumpulkan data hasil } \\
\text { Percobaan } \\
\text { Melakukan diskusi kelompok } \\
\text { Menyimpulkan hasil percobaan }\end{array}$ \\
\hline \multirow[t]{2}{*}{ Explanation } & $\begin{array}{l}\text { Mendorong peserta didik untuk } \\
\text { menjelaskan hasil percobaan. } \\
\text { Meminta peserta didik } \\
\text { pempresentasikan hasil } \\
\text { Percobaannya } \\
\text { Mengklarifikasikan hasil } \\
\text { Percobaannya } \\
\text { Menjelaskan konsep/definisi baru }\end{array}$ & $\begin{array}{l}\text { Mengemukakan pendapatnya } \\
\text { tentang hasil percobaan } \\
\text { Mengemukakan pendapatnya } \\
\text { tentang gagasan baru } \\
\text { berdasarkan hasil percobaan. } \\
\text { Menanggapi presentasi dari } \\
\text { kelompok lain. }\end{array}$ \\
\hline & & $\begin{array}{l}\text {-Konsep baru dari guru dapat di } \\
\text { Terima } \\
\end{array}$ \\
\hline Elaboration & $\begin{array}{l}\text { Memberi permasalahan berkaitan } \\
\text { dengan penerapan konsep. } \\
\text { Mendorong peserta didik untuk } \\
\text { menerapkan konsep baru dalam }\end{array}$ & $\begin{array}{l}\text { Menerapkan konsep baru dalam } \\
\text { situasi baru atau kehidupan } \\
\text { sehari-hari. }\end{array}$ \\
\hline
\end{tabular}




\begin{tabular}{|l|l|l|} 
& situasi baru & \\
\hline Write & $\begin{array}{c}\text { Memberi kesempatan kepada peserta } \\
\text { didik untuk mencatat hasil diskusi } \\
\text { serta kesimpulan. }\end{array}$ & $\begin{array}{c}\text { Mencatat hasil penjelasan dan } \\
\text { kesimpulan dari guru dan } \\
\text { diskusi kelompok }\end{array}$ \\
\hline Evaluation & Mengajukan pertanyaan untuk & Menjawab pertanyaan \\
& penilaian proses & berdasarkan data \\
& Menilai pengetahuan peserta didik & Mendemonstrasikan kemampuan \\
& Memberikan balikan terhadap & dalam penguasaan konsep \\
& jawaban peserta didik & \\
\hline
\end{tabular}


Sumber: Nana, Surahman E. 2019. Pengembangan Inovasi Pembelajaran Digital Menggunakan Model Blended POE2WE di Era Revolusi Industri 4.0. Prosiding SNFA (Seminar Nasional dan Aplikasinya), 82-90.

\subsection{Zenius Education}

Zenius Education merupakan perusahaan pendidikan yang secara de facto mulai beroperasi pada tahun 2004. Hingga saat ini tahun 2020 Zenius telah berkembang menjadi perusahaan pendidikan yang berbasis teknologi yang populer di Indonesia. Zenius education yang merupakan salah satu startup dengan platform pendidikan pertama yang beroperasi pada tahun 2004 yang berfokus pada layanan berbasis pendidikan yang mengajarkan konsep bukan hanya rumus cepat saja. saat ini, zenius dapat diakses secara gratis di aplikasi zenius education. Ini dapat memudahkan peserta didik untuk belajar di rumah dengan bantuan tutor online tanpa biaya.

Tabel 3. Tampilan aplikasi zenius education

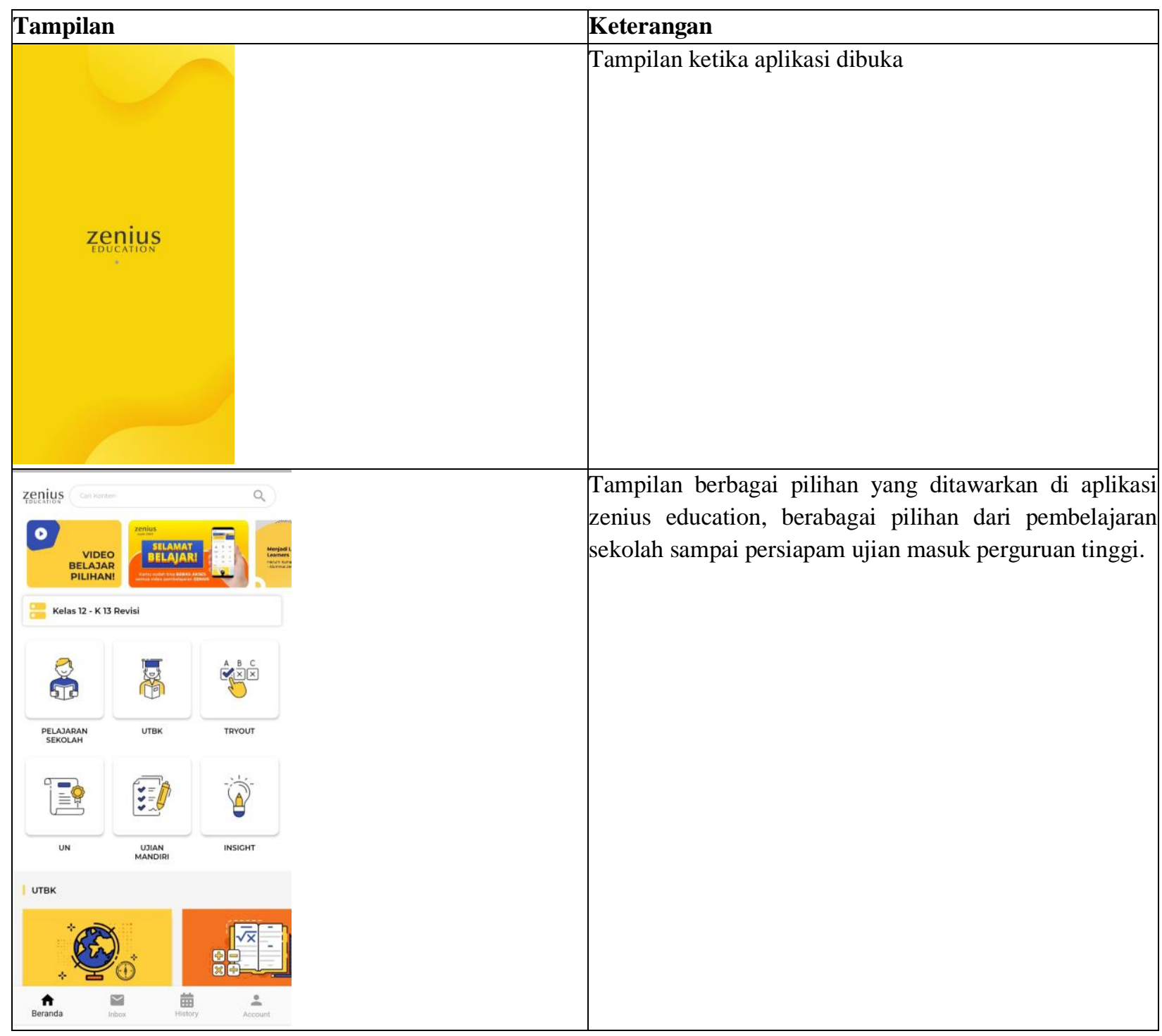




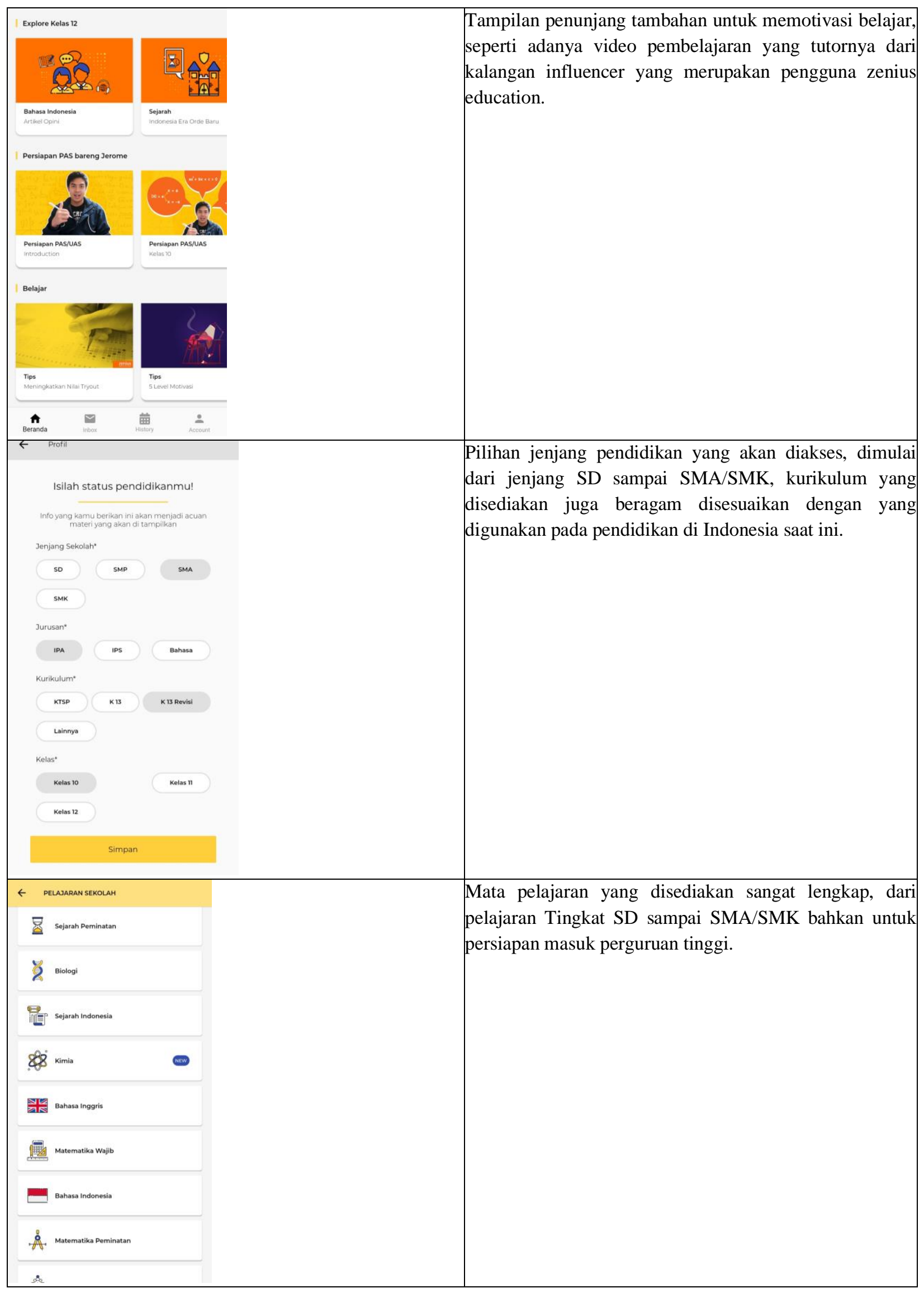




\subsection{Pembelajaran Fisika}

Pembelajaran adalah proses interaksi peserta didik dengan pendidik dan sumber belajar pada suatu lingkungan belajar. Pembelajaran merupakan bantuan yang diberikan pendidik agar dapat terjadi proses perolehan ilmu dan pengetahuan, penguasaan kemahiran dan tabiat, serta pembentukan sikap dan kepercayaan pada peserta didik. Dengan kata lain, pembelajaran adalah proses untuk membantu peserta didik agar dapat belajar dengan baik.

Fisika adalah sains atau ilmu alam yang mempelajari materi beserta gerak dan perilakunya dalam lingkup ruang dan waktu, bersamaan dengan konsep yang berkaitan seperti energi dan gaya. Salah satu ilmu sains paling dasar, tujuan utama fisika adalah memahami bagaimana alam semesta bekerja. Jadi, pembelajaran fisika adalah proses interaksi yang terjadi antara peserta didik dengan pendidik dengan pelajaran fisika pada suatu lingkungan belajar misalnya di sekolah.

Fisika merupakan mata pelajaran yang dapat menumbuhkan kemampuan pemecahan masalah siswa. Oleh karena itu, dalam pembelajaran fisika siswa dituntut untuk membangun dan menemukan sendiri pengetahuannya sehingga dapat memecahkan masalah fisika seperti pemahaman konsep fisika sehingga tidak terjadi miskonsepsi.

\subsection{Pengunaan Model Pembelajaran POE2WE dengan Bantuan Aplikasi Zenius Education untuk Meningkatkan Pemahaman Konsep dalam Pembelajaran Fisika}

Salah satu permasalahan peserta didik dalam belajar fisika yaitu dalam pembelajaran fisika terdapat banyak sekali rumus dengan simbol yang berbeda-beda. Rumus-rumus itu membuat peserta didik malas untuk belajar fisika. Peserta didik berfikir bahwa rumus itu susah untuk dihafal. Padahal, rumus itu bukan untuk dihapal tetapi perlu dipahami, maka belajar fisika itu harus dimulai dari konsepnya sehingga ketika penggunaan rumus tidak akan membingungkan karena sudah mengerti dari akarnya.

Model POE2WE merupakan model pembelajaran yang dikembangkan untuk mengetahui pemahaman siswa mengenai suatu konsep dengan pendekatan konstruktivistik. Model ini membangun pengetahuan dengan urutan proses terlebih dahulu meramalkan atau memprediksi solusi dari permasalahan, melakukan eksperimen untuk membuktikan prediksi, kemudian menjelaskan hasil eksperimen yang diperoleh secara lisan maupun tertulis, membuat contoh penerapan dalam kehidupan sehari-hari, menuliskan hasil diskusi dan membuat evaluasi tentang pemahaman siswa baik secara lisan maupun tertulis (Nana, 2018). Model POE2WE dapat meningkatkan pemahaman konsep karena tiap langkahnya selalu dihubungkan dengan fenomena-fenomena yang terjadi secara langsung.

Aplikasi Zenius Education juga dapat menigkatkan pemahaman konsep dalam pembelajaran fisika. Berdasarkan pengalaman penulis menggunakan aplikasi Zenius Education, pembelajaran yang disajikan benar-benar dengan konsep, dan dijelaskan secara detail dan membuat kegiatan belajar jadi menarik. Video pembelajaran pada aplikasi Zenius Education tidak hanya memberikan rumus saja, tetapi menjelaskan darimana rumus itu didapat, dan apa makud dari rumus tersebut. Dijelaskan pula sebelum belajar materi, apa saja yang perlu dipersiapkan ketika akan mempelajari materi tersebut. Termasuk ketika belajar fisika, Zenius Education telah menyiapkan starting Physics-nya.

Jadi antara model POE2WE dan aplikasi zenius education, sama-sama mengajari dari kosnsep sehingga akan saling melengkapi. Jika model POE2WE dapat diterapkan di sekolah oleh pengajar, maka jika di rumah peserta didik dapat menggunakan aplikasi Zenius Education secara gratis, unuk menambah pemahaman dan mengulang kembali pelajaran yang telah disampaikan di sekolah.

\section{PENUTUP}

Dari beragai pembahasan yang telah diuraikan, kesimpulan yang dapat ditarik bahwa model pembelajaran POE2WE dan penggunaan aplikasi zenius education dapat meningkatkan pemahaman konsep 
pembelajaran fisika, karena baik model POE2WE maupun aplikasi Zenius Education sama-sama mengenalkan konsep.

\section{UCAPAN TERIMA KASIH}

Terima kasih kepada semua pihak yang mendukung dan membantu dalam penyusunan artikel ini. Terima kasih kepada Dr. Nana, M.Pd. yang telah membimbing dalam penyusunan artikel ini.

\section{Daftar Pustaka}

Brush, T., Glazewski, K. D. and Hew, K. F. (2008). Development of an dimensit to measure preservice teachers' technology skills, technology beliefs, and technology barriers. Computers in the Schools, vol. 25, pp.112-125.

Lee, Y. J. (2011). A study on the effect of teaching innovation on learning effectiveness with learning satisfaction as a mediator. World Transactions on Engineering and Technology Education, 9 (2), 92-101. Lin

Nana, Sajidan, Akhyar, M., \& Rochsantiningsih, D.. Pengembangan Pembelajaran Fisika SMA Melalui Elaboration Write dan Evaluation (EWE) dalam Kurikulum 2013.

Nana. (2018, Oktober 27). Implementasi Model POE2WE dengan Pendekatan Saintifik dalam Pembelajaran Gerak Lurus di SMA. Seminar Nasional Pendidikan Sains, 18. Dipetik Februari 17, 2020

Nana, Sajidan, Akhyar, M., \& Rochsatiningsih, D. (2014). The development of Predict, Observe, Explain, Elaborate, Write, and Evaluate (POE2WE) Learning Model in Physics Learning at Senior Secondary School. Journal of Education and Practice, 5(19), 56-65

Nana, Rochsanriningsih, D., Akhyar, M., \& Sajidan. (2016). The Effectiveness of Scientific Approach Through Predict, Observe, Explain, Elaborate, Write and Evaluate (POE2WE) Model on the Topic of Kinematics (Rectilinear Motion) at Senior High School. The Social Sciences, 11(6), 1028-1034.

Nana dan Surahman E. (2020). POE2WE Model as an Alternative for Learning Physics in Industrial Revolution 4.0 Era. Advances in Social Science, Education and Humanities Research, 397(2), $1013-1022$

Nana, Surahman E. (2019). Pengembangan Inovasi Pembelajaran Digital Menggunakan Model Blended POE2WE di Era Revolusi Industri 4.0. Prosiding SNFA (Seminar Nasional dan Aplikasinya), 8290. 